\title{
Coulisses
}

Revue de théâtre

5 | Hiver 1992

Varia

\section{H20, Madame, de la rue piétonne à la mer d'Aral}

\author{
Isabelle Drouot
}

\section{OpenEdition}

Journals

Édition électronique

URL : http://journals.openedition.org/coulisses/1719

DOI : 10.4000/coulisses. 1719

ISSN : 2546-9460

\section{Éditeur}

Presses universitaires de Franche-Comté

\section{Édition imprimée}

Date de publication : 1 janvier 1992

Pagination : 31-32

ISSN : 1150-594X

\section{Référence électronique}

Isabelle Drouot, «H20, Madame, de la rue piétonne à la mer d'Aral », Coulisses [En ligne], 5 | Hiver 1992 mis en ligne le 04 juillet 2017, consulté le 21 octobre 2019. URL : http://journals.openedition.org/ coulisses/1719; DOI : 10.4000/coulisses.1719

Ce document a été généré automatiquement le 21 octobre 2019

Coulisses 


\title{
H20, Madame, de la rue piétonne à la mer d'Aral
}

\author{
Isabelle Drouot
}

Rue piétonne à Besançon, mercredi 26 juin 1991, des larmes ont rejoint la chaîne de l'eau qui doit faire renaître la mer d'Aral.

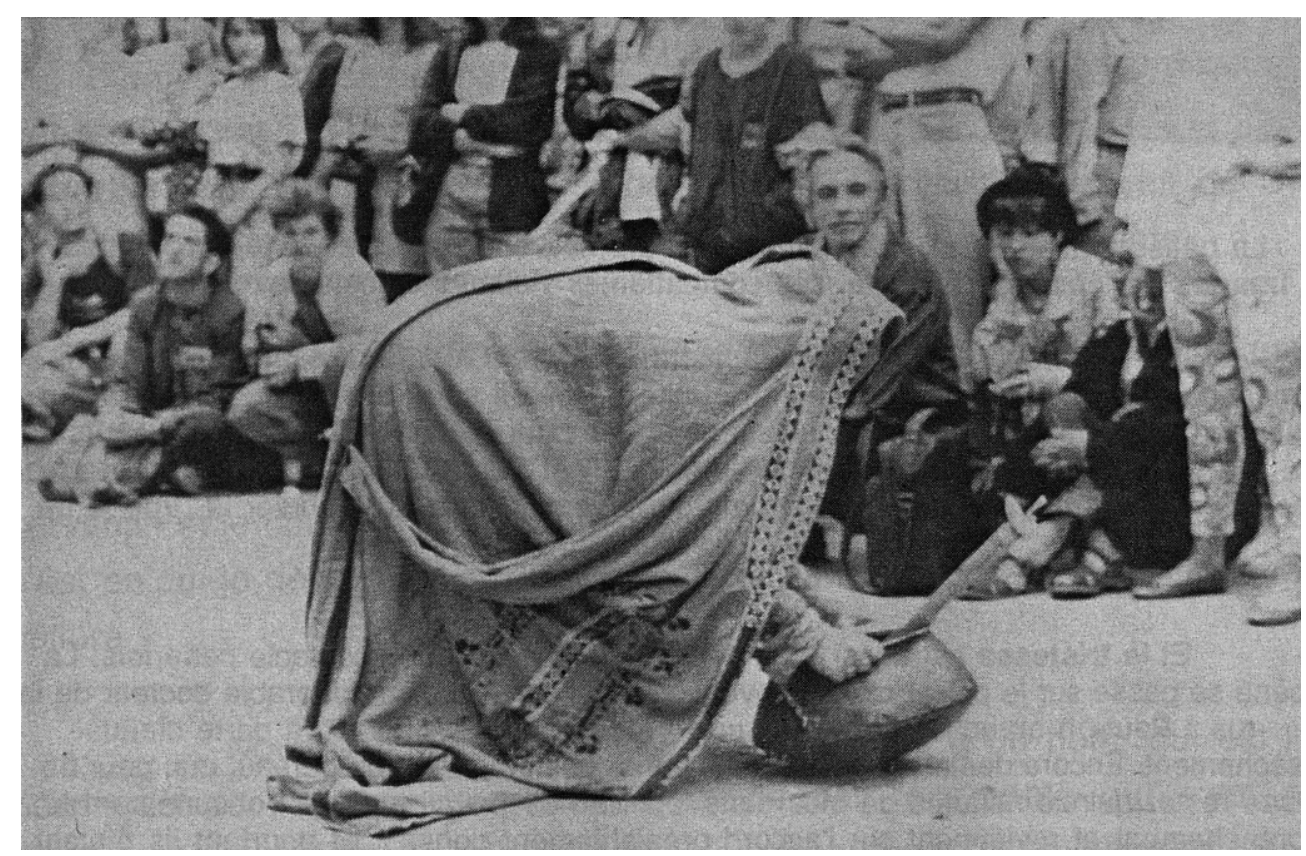

H20, Madame : photo P. Dery, Hull collège, Québec.

2 Il faut prendre conscience de l'irrémédiable. La détresse de ces femmes est assez immense pour couvrir le monde, le message qu'elles veulent insuffler à tous les peuples est universel et transcende les frontières. Il ne peut laisser indifférent car la tragédie qui se joue là-bas, à quatre jours de train, est aussi la nôtre.

3 Les Taschkent ont fait souffler un vent de révolte en tous ceux qui ont pris le temps d'en perdre un peu. Ces saltimbanques dérisoires et fiers, dans leurs costumes 
resplendissants de simplicité, derniers lambeaux d'une terre condamnée, nous livrent un message bouleversant : l'eau, source de vie se tarit. Sa disparition ouvre les portes de la mort et le retrait des flots découvre une terre brulée.

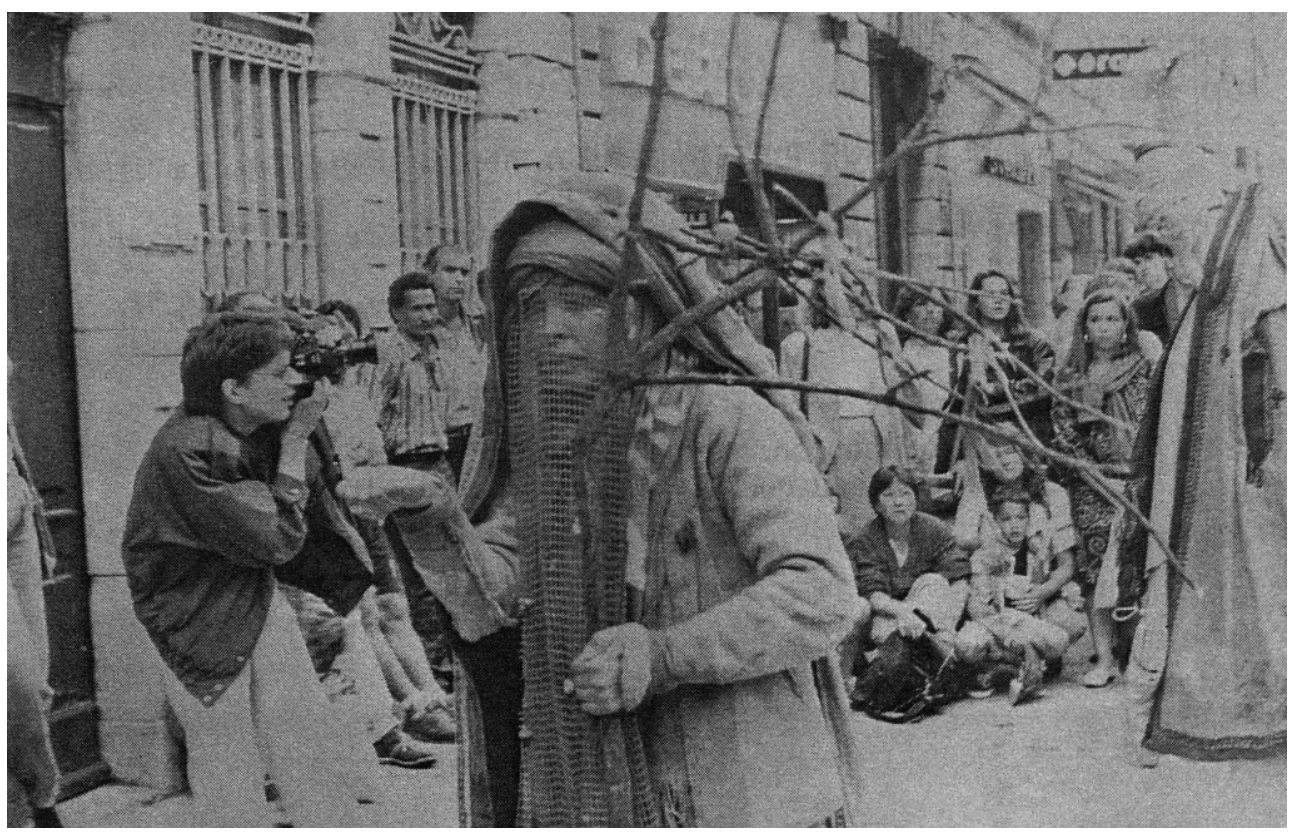

H20, Madame : photo P. Dery, Hull collège, Québec.

4 La bêtise destructrice est partout. Sans un mot, en un cri, par le langage des images et l'émotion du geste, ces combattantes victimes lancent l'avertissement...

5 A nous de saisir, de le transmettre, de créer un fleuve planétaire qui reconduise vite l'eau où l'homme l'a détruite; après il sera trop tard... Mais si l'eau est chère à ce peuple fantôme, elle l'est de même pour certains "pauvres" résidents de la rue piétonne pas trop concernés, semble-t-il, et qui, pour beaucoup d'entre-eux, refusèrent les quelques litres et le petit dérangement qu'a dû mendier la troupe de Taschkent.

6 Et la tristesse est aussi chez nous, mais pas dans le spectacle cette fois. La scène se passe sur le pallier d'une convenable habitante ou d'un honorable docteur de la rue : Peut-on brancher un tuyau sur un robinet c'est pour... et la porte claque sèchement. Encore des mendiants! Sans parler des employés de bureau, qui, pour ne pas rester quinze minutes de plus dans leur lieu de travail, refusent obstinément le branchement et reviennent sur l'accord préalablement donné. Et pourtant ils étaient aux premières loges! Et voilà que, sans la volonté de certains autres voisins bénis, la somme immense d'énergie qu'il a fallu déployer pour que le spectacle soit donné a manqué d'être anéantie.

7 Enfin le bonheur du spectacle, c'est lorsque la conscience déclenche l'action. C'est la mobilisation pour que le spectacle ait lieu malgré tout et pour que l'eau devenue parole puisse faire jaillir son appel. Et tout le public adhère au canal, porte le flot qui doit faire renaître la mer d'Aral qui agonise...

8 Ainsi la révolte contre la mort de l'eau, c'est aussi celle envers la mesquinerie, la cécité d'âme qui refuse de considérer l'ampleur du désastre qui se joue là-bas... pour l'instant. 